\title{
Jovem ciclista claudicante: situação preocupante
}

Alexandra Duarte,* Lígia Torres Lima,* Joana Neto,* Mónica Barbosa*

\section{RESUMO}

Introdução: A claudicação intermitente é uma queixa relativamente comum nos Cuidados de Saúde Primários, estando geralmente associada ao envelhecimento e à aterosclerose generalizada. No entanto, na população jovem-adulta sem fatores de risco é um sintoma extremamente raro.

Descrição do caso: Ciclista profissional de 26 anos de idade, com claudicação intermitente de agravamento progressivo e cujo diagnóstico foi realizado cerca de seis meses após o início da sintomatologia quando apresentava já claudicação incapacitante. Durante este período de tempo consultou médicos de diferentes especialidades e realizou vários estudos imagiológicos que não demonstraram alterações. Trata-se de um caso de estenose ilíaca não aterosclerótica, com recidiva pós-cirúrgica e durante intervenção medicamentosa que o obrigou a abandonar a carreira numa idade precoce.

Comentário: Em jovens com queixas de dor ou impotência funcional com o exercício, mesmo sem qualquer fator de risco de doença aterosclerótica, a possibilidade de doença arterial obstrutiva deverá ser investigada. A endofibrose ilíaca está subdiagnosticada no nosso país, sendo frequente em desportistas de alta competição. Serve assim o presente caso para alertar e sensibilizar os médicos de família para uma situação que, embora rara, existe e que requer um diagnóstico precoce numa tentativa de minimizar as complicações potencialmente graves.

Palavras-chave: Claudicação Intermitente; Ciclismo; Doença Arterial Oclusiva.

\section{INTRODUÇÃO}

A claudicação intermitente é uma queixa relativamente comum nos cuidados de saúde primários, que decorre sobretudo de uma isquemia crónica dos membros inferiores. Está geralmente associada ao envelhecimento e à aterosclerose generalizada, com todos os seus fatores de risco conhecidos, nomeadamente diabetes mellitus, hipertensão arterial, dislipidemia e tabagismo. No entanto, na população jovem-adulta e sem fatores de risco é um sintoma extremamente invulgar, que raramente nos leva a pensar em doença arterial oclusiva. Não obstante, cabe ao Médico de Família (MF) estar alerta, pois existem etiologias de quadros de isquemia dos membros inferiores não ateroscleróticas que deverão ser consideradas na abordagem de indivíduos nesta faixa etária com queixas sugestivas de claudicação intermitente. Adicionalmente, face a jovens-adultos desportistas, profissionais ou não, sem fatores de

*Médicas internas de Medicina Geral e Familiar - USF S. João de Sobrado, ACES Maia/Valongo risco de aterosclerose, nos quais as queixas musculares são frequentes e facilmente associadas ao esforço físico e traumatismos, o índice de suspeição deverá ser elevado, de forma a evitar diagnósticos tardios de situações mais graves e com potenciais complicações.

As autoras apresentam um caso clínico de um ciclista profissional, sem antecedentes patológicos relevantes, a quem foi diagnosticada uma entidade rara endofibrose ilíaca - com necessidade de intervenções cirúrgicas e consequente impacto a nível psicológico, orgânico e social.

\section{DESCRIÇÃO DO CASO}

Descreve-se o caso de jovem de 26 anos do sexo masculino, ciclista profissional, inserido numa família nuclear altamente funcional, na fase I do ciclo de Duvall e pertencente à classe média de Graffar. Não tem antecedentes patológicos de relevo, nem hábitos alcoólicos ou tabágicos, referindo uma alimentação saudável.

Em maio de 2009 encontrava-se em fase de preparação para o Campeonato Nacional de Estrada, período em que aumentou a duração e intensidade dos trei- 
nos e redobrou cuidados com a alimentação, perdendo algum peso, tendo em vista a melhoria do rendimento na competição. Durante um treino iniciou quadro de dor no membro inferior esquerdo (MIE), desde a região glútea até ao joelho, associada a sensação de diminuição de força muscular e "membro preso". Fora dos períodos de treino, e mesmo durante as atividades do dia-a-dia, sentia um desconforto em todo o MIE. A dor evoluiu com agravamento progressivo e limitação funcional concomitante durante uma semana. Foi possível a participação na referida competição, em junho, a qual realizou sem limitação, referindo, contudo, manutenção de um certo desconforto muito inespecífico do MIE. Participou ainda, em agosto, na Volta a Portugal em Bicicleta sem qualquer tipo de queixa.

Após este período de esforço mais intenso referiu recorrência dos sintomas, com dor e um "prender de movimento" ao nível do MIE, apenas durante os treinos de bicicleta (claudicação intermitente, por vezes, incapacitante), permanecendo com um "desconforto estranho" em repouso e nas atividades da vida quotidiana. Pensando que provavelmente se tratava de uma lesão a nível muscular recorreu a tratamentos de fisioterapia, com o objetivo de tratar uma possível rotura muscular, os quais não se revelaram eficazes, verificando-se persistência do quadro clínico.

Numa tentativa de perceber o que se passava recorreu a alguns médicos, inclusive médicos especialistas em medicina desportiva, que lhe propuseram a realização de vários exames complementares de diagnóstico cujos resultados não evidenciaram qualquer alteração que justificasse os sintomas do ciclista.

Em outubro de 2009, por agravamento das queixas de claudicação intermitente (agora permanentemente incapacitantes) e por sentir o pé esquerdo mais frio que o direito, recorreu ao serviço de urgência (SU) do seu hospital de referência, onde lhe foi detetado, após exame físico dirigido, ausência de pulsos pedioso e tibial posterior à esquerda. Realizou ecodoppler dos membros inferiores (MIs), que revelou uma redução significativa do índice tornozelo/braço ao nível do MIE em relação ao do MI contralateral. Foi levantada a suspeita de uma estenose vascular do MIE com necessidade de investigação adicional. Assim, realizou angiotomografia (angioTC) que confirmou a presença de "estenose sem aterosclerose na artéria ilíaca externa esquerda, com uma extensão de cerca de $6 \mathrm{~cm}$ ". Já em consulta externa de cirurgia vascular no mesmo hospital, após exclusão de fatores de risco para doença arterial periférica, nomeadamente trombofilias, foi confrontado com o diagnóstico de endofibrose ilíaca. Foi informado de que a prática de ciclismo profissional terá sido o fator predisponente para o desenvolvimento desta anomalia arterial e que teria de abandonar a sua carreira de ciclista.

Inconformado e descrente com o diagnóstico apresentado e, sobretudo, pela ausência de uma solução para o seu caso, decidiu ouvir uma segunda opinião, tendo sido observado noutro centro hospitalar. Perante o quadro clínico e resultado da angioTC foi-lhe proposta a realização de um bypass que lhe permitiria regressar à competição. Foi submetido, em fevereiro de 2010, a bypass ilio-femoral esquerdo com prótese vascular de politetrafluoroetileno de $8 \mathrm{~mm}$ reforçada. No pós-operatório manteve a prótese funcionante, com pulsos periféricos palpáveis. Teve alta 8 dias depois, medicado com antiagregante (clopidogrel $75 \mathrm{mg} /$ dia) e com indicação para regressar aos treinos um mês depois.

Após aval médico para regressar às competições reiniciou treinos sem qualquer tipo de limitação. Inicialmente sentia medo e pouca confiança nele próprio, conseguindo recuperar aos poucos a forma física.

Em maio de 2010 voltou a competir, verificando a recorrência da dor incapacitante que tinha antes da cirurgia. Voltou a realizar ecodoppler arterial do MIE, que revelou trombose completa da prótese ilío-femoral interposta à esquerda com cerca de $3 \mathrm{~cm}$. No mês seguinte foi reintervencionado para desobstrução do bypass com trombectomia, que decorreu sem intercorrências. Realizou angioTC de controlo, que não evidenciou qualquer alteração, mantendo-se a prótese funcionante.

Em setembro de 2010, apesar de assintomático, tomou a decisão de abandonar a carreira de ciclista profissional, por receio de nova recorrência obstrutiva a nível ilio-femoral. Iniciou nova atividade profissional numa empresa de mobiliário e começou a praticar futebol amador uma vez por semana.

Permaneceu assintomático até janeiro de 2012, altura em que a dor com limitação funcional ao nível do MIE surgiu novamente, mantendo as características previamente descritas. Descontente com as intervenções médica e cirúrgica recebidas previamente, decidiu recorrer a um terceiro cirurgião vascular, médico no seu hospital 


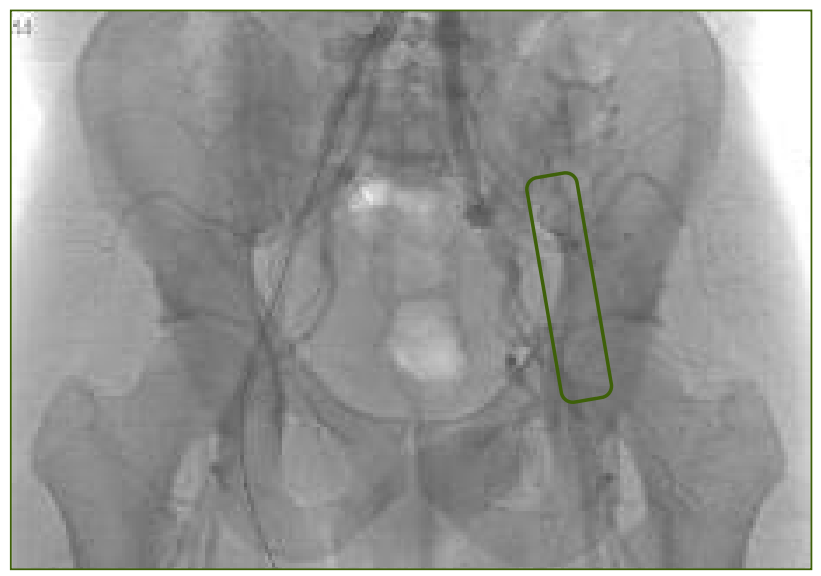

Figura 1. Arteriografia dos Mls, que evidencia estenose da prótese ilio-femoral esquerda.

de referência. Em abril, após repetição da arteriografia dos MIs (figura 1), constatou-se reestenose da prótese ilio-femoral com isquemia de grau $2 \mathrm{~b}$ à esquerda.

Após estudo do caso, a equipa médica decidiu não proceder a nova intervenção cirúrgica, aconselhando o doente a fazer evicção total de prática desportiva pelo risco de agravamento da estenose. Optou-se, assim, por manter terapêutica antiagregante e seguimento regular em consulta de cirurgia vascular.

Sendo, neste contexto, a estenose da artéria ilíaca sem aterosclerose (ou endofibrose ilíaca) uma doença profissional, este jovem vê a sua carreira e o seu gosto pelo ciclismo comprometidos.

\section{COMENTÁRIO}

Nos utentes jovens, desportistas, com queixas de dor ou impotência funcional para o exercício, mesmo sem qualquer fator de risco de doença aterosclerótica, a possibilidade de doença arterial obstrutiva deverá ser tida em consideração. A endofibrose ilíaca está subdiagnosticada no nosso país e foi mais frequentemente descrita em ciclistas (cerca de 90\%), desde os amadores aos profissionais, mas também em maratonistas, atletas de triatlo, jogadores de rugby e de futebol, patinadores de velocidade, esquiadores (cross country skiers) e culturistas. ${ }^{1-2}$ Em Portugal foi publicado apenas um artigo, em 2008, que descreve um caso semelhante, de uma jovem de 31 anos de idade, desportista de alta competição (triatlo, com realização de treinos diários, corrida, ciclismo e natação, com durações superiores a duas horas). ${ }^{3}$ Esta condição é mais frequente nos homens (93\% dos doentes operados eram do sexo masculino), principalmente a nível do ciclismo, certamente influenciado pela elevada percentagem de homens que participam neste desporto e pelas diferenças na carga de trabalho durante o treino. A proporção entre os sexos é de cerca de $50 \%$ para outros desportos. ${ }^{2}$

A endofibrose ilíaca é geralmente assintomática em repouso, surgindo uma claudicação intermitente, incapacitante durante o esforço máximo de exercício. Como surge principalmente em atletas de alta competição, esta sintomatologia é muitas vezes atribuída ao aparelho músculo-esquelético. $\mathrm{O}$ atraso no seu diagnóstico deve-se, entre outros, ao facto de realizarem primeiramente fisioterapia e, só por persistência dos sintomas, procurarem outras causas. Foi apenas nos anos 80 que foi sugerida a insuficiência arterial não-aterosclerótica como causa deste tipo de sintomatologia. ${ }^{1}$ Histologicamente caracteriza-se por uma fibrose paucicelular da camada subentotelial íntima, que leva ao espessamento progressivo da parede arterial e, consequentemente, à redução do seu lúmen. ${ }^{2}$ Localiza-se, em $90 \%$ dos casos, na artéria ilíaca externa, mas pode estar presente noutras localizações, como na ilíaca comum, femoral ou femoral profunda. ${ }^{2}$

Deve realçar-se o facto de este jovem ter solicitado a opinião de alguns médicos e técnicos de saúde, sem nunca ter procurado o seu MF com as queixas de claudicação, tendo este tido conhecimento da história clínica apenas na sua fase final. Poderia ter sido importante como fio orientador e condutor da situação, integrando precocemente todo o conhecimento prévio que teria do jovem com a sintomatologia por ele apresentada, solicitando os exames complementares de diagnóstico necessários e referenciando em maior tempo útil. É certo que este é um diagnóstico difícil e raro e que os atletas são seguidos a nível da medicina desportiva, mas devemos ter em atenção que temos no país cada vez mais desportistas (federados ou não) e que o ciclismo está na moda. Parece, assim, fundamental proporcionar ao MF mais formação na área da medicina desportiva, no sentido de este atuar não só na motivação e prescrição de atividade física, mas também na prevenção de lesões induzidas pelo desporto e tratamento/referenciação precoces de situações sequelares a traumatismo físico. 
Outro ponto importante é a classificação, ou não, deste caso como doença profissional. Não estando esta patologia presente na Lista das Doenças Profissionais, ${ }^{4}$ o jovem viu a sua carreira profissional comprometida, sendo forçado a mudar de área laboral. Neste momento, ainda decorre o seu processo em tribunal para atribuição de doença profissional.

Temos, assim, um jovem adulto, agora com 30 anos de idade, a fazer terapêutica antiagregante e com o sonho profissional destruído. Mudou de emprego, casou, tem uma filha de 12 meses e uma vida estabilizada. No entanto, devemos ter em atenção que as suas perspetivas (relacionadas com o desporto) ficaram severamente danificadas. O impacto psicológico da doença, assim como as suas repercussões, poderão ser marcantes se não existir um bom suporte que deverá englobar a família e amigos, assumindo também aqui o MF um importante papel. Este deverá estar atento aos comportamentos e queixas do doente, dado o elevado risco da emergência de sintomas ansiosos, depressivos e até de alterações da dinâmica familiar e social. O profissional deverá, assim, investir numa relação de confiança, empatia e respeito, integrando o doente numa perspetiva biopsicossocial, ajudando-o a lidar com a incapacidade física e planos de vida subitamente frustrados. O objetivo será manter um seguimento regular, auxiliando na preservação do equilíbrio emocional, da autoestima, das relações familiares e de amizade e na procura de alternativas de futuro.

Serve, assim, o presente caso para alertar e sensibilizar os médicos de família para uma situação que, embora rara, existe e que requer um diagnóstico precoce, numa tentativa de minimizar as complicações potencialmente graves.

\section{REFERÊNCIAS BIBLIOGRÁFICAS}

1. Peach G, Schep G, Palfreeman R, Beard JD, Thompson MM, Hinchliffe RJ. Endofibrosis and kinking of the iliac arteries in athletes: a systematic review. Eur J Vasc Endovasc Surg. 2012;43(2):208-17.

2. Feugier $P$, Chevalier J. Endofibrosis of the iliac arteries: an underestimated problem. Acta Chir Belg. 2004;104(6):635-40.

3. Carmo G, Rosa A, Ministro A, Cunha e Sá C, Pestana C. Isquemia crónica dos membros inferiores, de etiologia não aterosclerótica, em desportistas jovens [Non-atherosclerotic lower limbs ischemia in young athletes]. Rev Port Cir Cardio Tor Vasc. 2008;15(3):157-61. Portuguese

4. Decreto Regulamentar ${ }^{\circ} 76 / 2007$, de 17 de julho. Diário da República. $1^{\mathrm{a}}$ série(136).

\section{CONFLITO DE INTERESSE}

As autoras declaram não possuir conflito de interesses.

\author{
ENDEREÇO PARA CORRESPONDÊNCIA \\ Joana Neto \\ Rua Santos Pousada, $n^{\circ} 974,3^{\circ}$ esq. $4000-482$ Porto \\ E-mail:jananeto@gmail.com
}

Recebido em 07-04-2014

Aceite para publicação em 29-07-2014

\section{ABSTRACT}

\section{CLAUDICATION IN A YOUNG CYCLIST: A WORRISOME SITUATION}

Introduction: Intermittent claudication is a familiar complaint in Primary Health Care and is associated with aging and atherosclerosis. However, in the young adult without risk factors, it is extremely rare.

Case report: A 26 year-old professional cyclist presented with progressive worsening of intermittent claudication. The diagnosis was made six months after the onset of symptoms, when incapacitating claudication was already present. During this time he was seen by several doctors from different specialties and underwent various imaging studies, which did not demonstrate abnormalities. lliac artery atherosclerotic stenosis was diagnosed, with recurrence after surgery and during medical treatment. This forced him to abandon his career at an early age.

Comment: In young patients with complaints of pain or functional disability with exercise, even without risk factors for atherosclerotic disease, the possibility of arterial disease should be investigated. Iliac artery endofibrosis is under-diagnosed in our country. It is more common in high-level competitive athletes. This case is presented to alert and sensitize family doctors to a rare diagnosis that requires early diagnosis to prevent potentially serious complications.

Keywords: Intermittent Claudication; Bicycling; Arterial Occlusive Disease. 